\title{
Layered Hydrogel with Controllable Surface Dissociation for Durable
}

\section{Lubrication}

Minghai $Q u^{a, b \#}$, Hui Liu ${ }^{b, c \#}$, Changyou Yan ${ }^{b, c}$, Shuanhong Ma ${ }^{b *}$, Meirong, Cai ${ }^{b}$, Zhengfeng $M a^{b}$, Feng Zhou ${ }^{b^{*}}$

${ }^{a}$ College of Textile and Clothing Engineering, Dezhou University, Dezhou 253023, China.

${ }^{b}$ State Key Laboratory of Solid Lubrication, Lanzhou Institute of Chemical Physics, Chinese Academy of Sciences, 18 Middle Tianshui Road, Lanzhou, 730000, China.

'University of Chinese Academy of Sciences, Beijing 100049, China.

Email: mashuanhong@licp.cas.cn;zhouf@licp.cas.cn

${ }^{\#}$ Minghai Qu and Hui Liu contribute equally to this work.

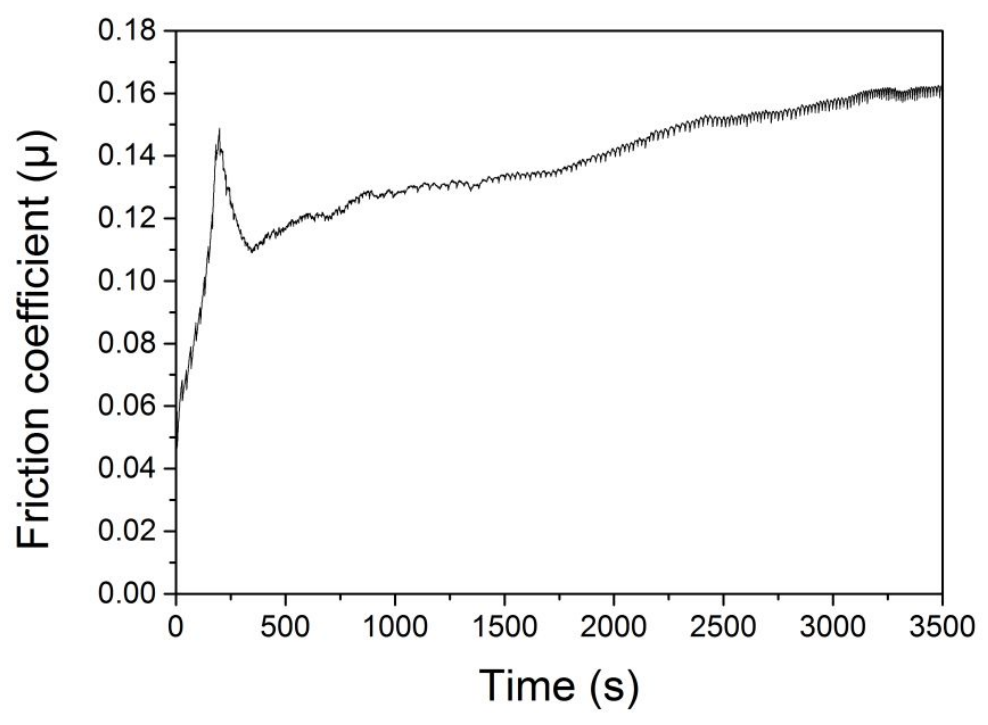

Figure S1. COF curve of control PAA-Fe/PAM hydrogels sheet. 

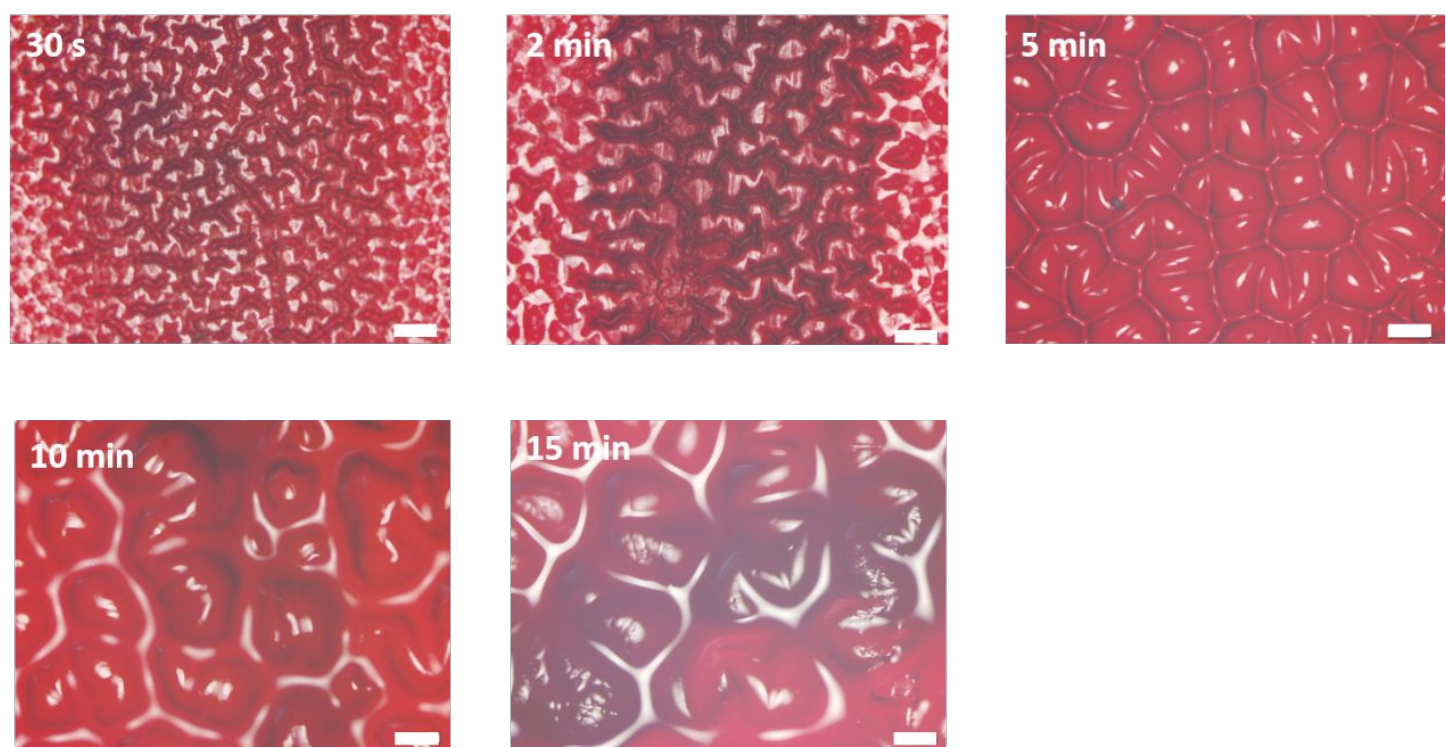

Figure S2. Optical images of layered hydrogels samples with different $\mathrm{NaOH}$ treatment time after getting through 3600 cycles friction test (Load: $5 \mathrm{~N}$; frequency: $1 \mathrm{~Hz}$ ) (scale bar: $200 \mu \mathrm{m})$.

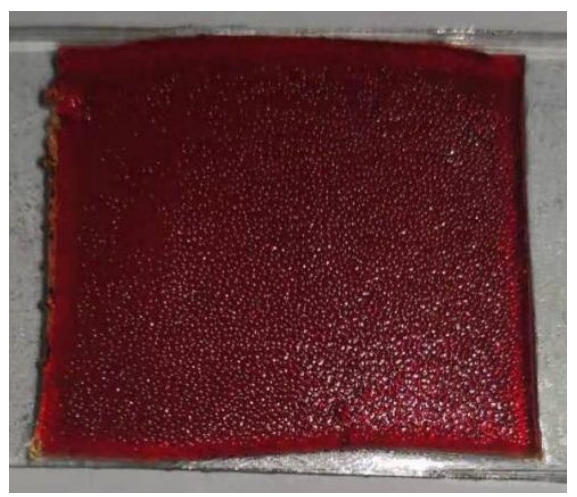

Figure S3. Photography of layered hydrogels sample with 5 min $\mathrm{NaOH}$ treatment upon encountering 3600 cycles friction test (load: $5 \mathrm{~N}$; frequency: $1 \mathrm{~Hz}$ ). 


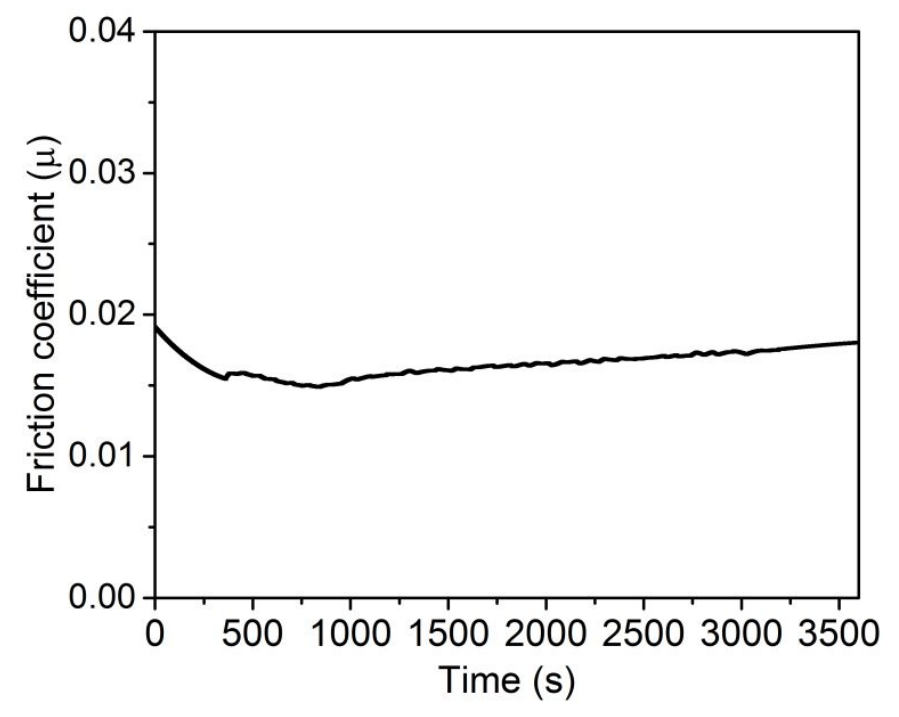

Figure S4. The curve of friction coefficient for layered hydrogel sample when PBS media was used as lubricant.

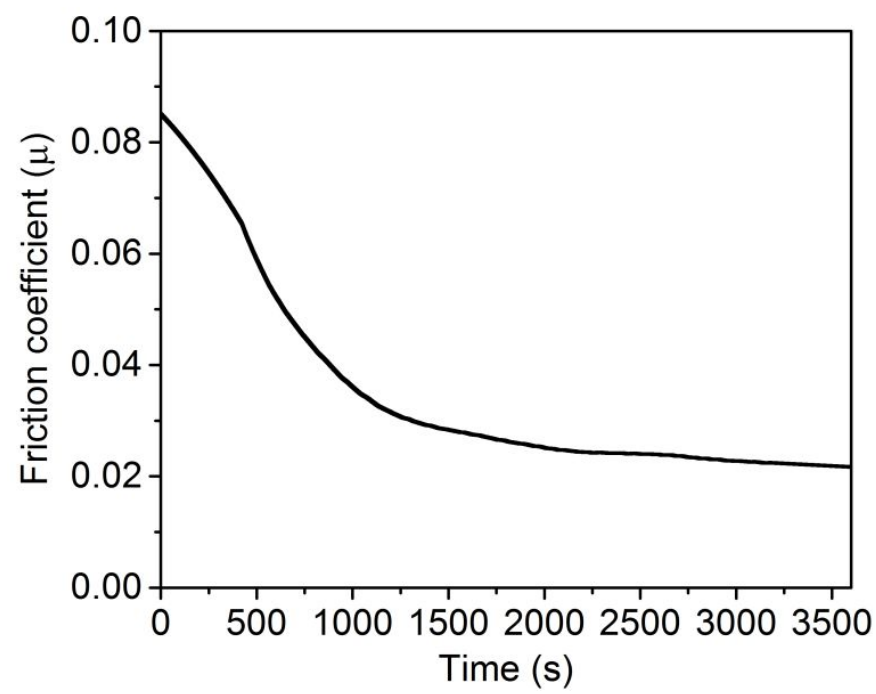

Figure S5. The curve of friction coefficient for layered hydrogel sample when normal saline media was used as lubricant. 


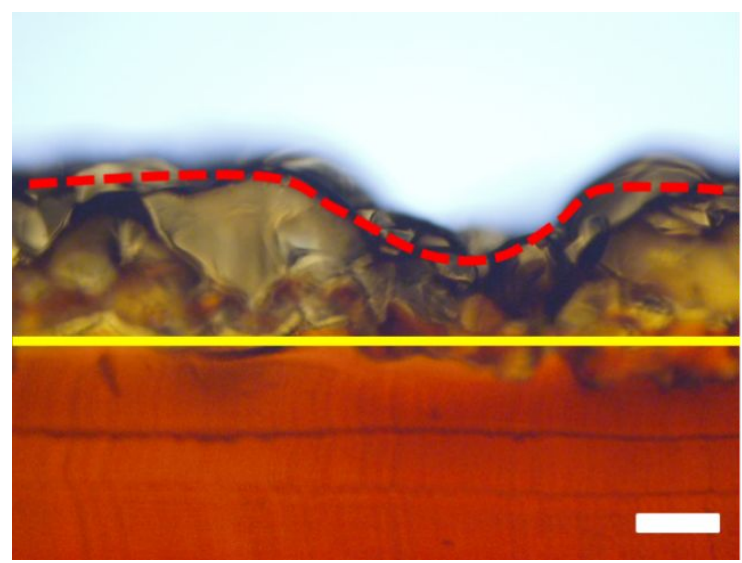

Figure S6. Cross-section optical image showing the morphology of the layered hydrogels sample with 5 min $\mathrm{NaOH}$ treatment upon encountering 50000 test cycles under high load of $10 \mathrm{~N}$ at the frequency of $1 \mathrm{~Hz}$ (the yellow line represents the interface of top lubrication layer and bottom support layer, and the red line indicates the wear profile of top lubrication layer at the middle contact area of the steel ball against the sample) (scale bar: $100 \mu \mathrm{m}$ ).

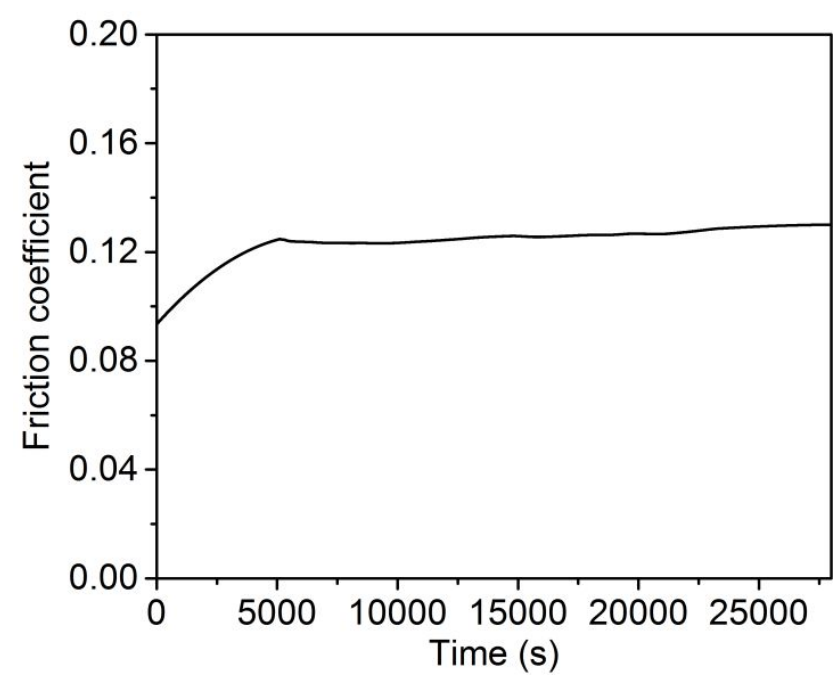

Figure S7. Long time friction test of control hydrogel sample for 28000 sliding cycles at a constant frequency of $1 \mathrm{~Hz}$ under a $10 \mathrm{~N}$ load (pair: $6 \mathrm{~mm}$ steel ball; lubricant: water).

a

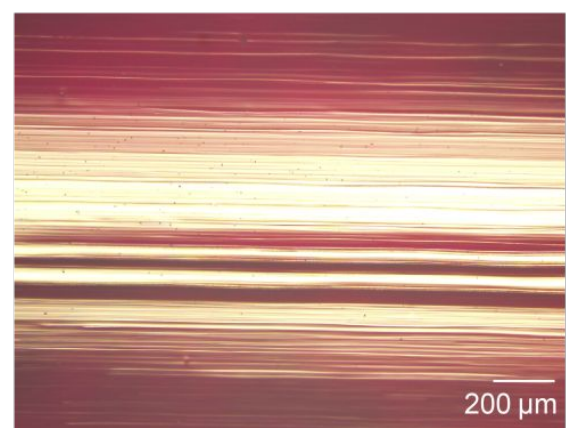

b

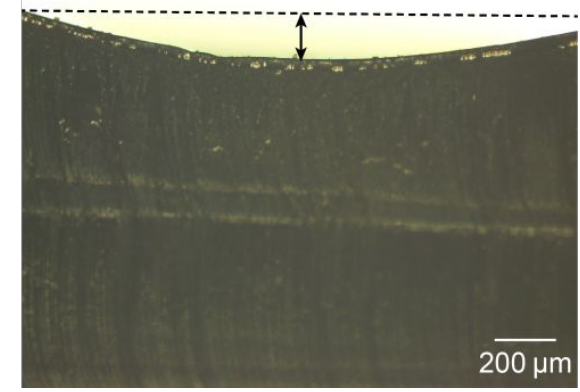


Figure S8. (a) The optical image showing the top surface morphology of control hydrogel sample after getting through long time friction test (28000 cycles). (b) Crosssection optical image showing the morphology of the control hydrogel sample upon encountering 28000 cycles.
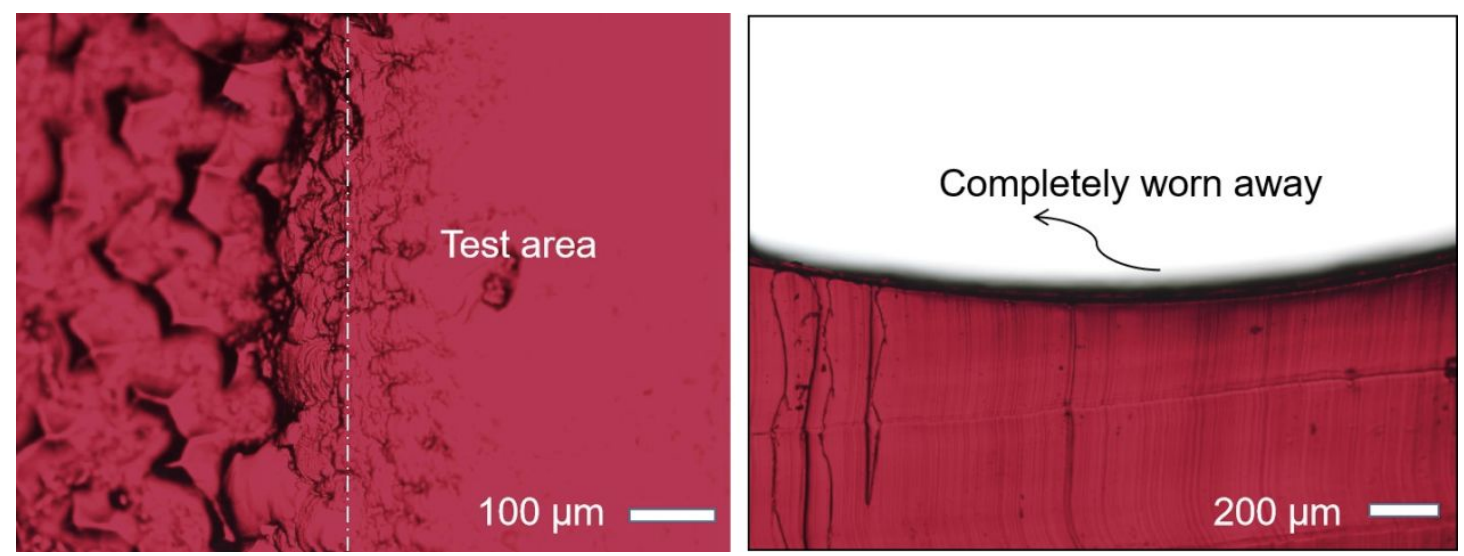

Figure S9. Surface (left) and cross-section (right) optical images showing the morphologies of the layered hydrogel sample with 5 min $\mathrm{NaOH}$ treatment after encountering 16000 test cycles under high load of $20 \mathrm{~N}$ at the frequency of $1 \mathrm{~Hz}$.

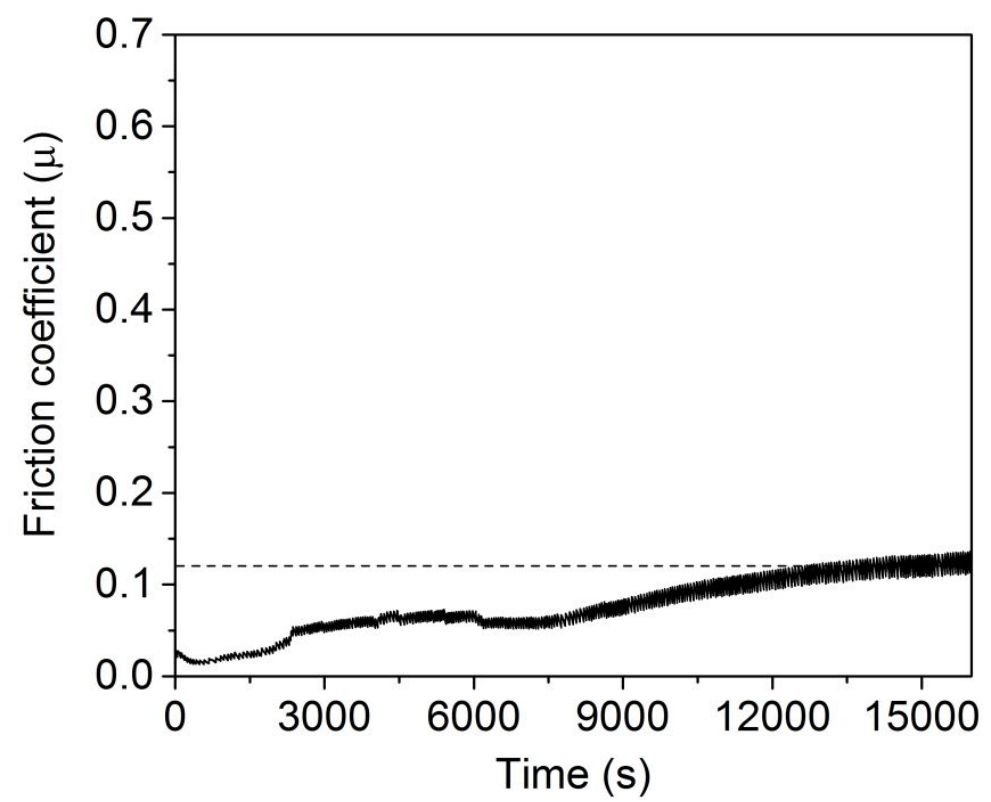

Figure S10. Long time friction test of the layered hydrogels material with $5 \mathrm{~min} \mathrm{NaOH}$ treatment for 16000 sliding cycles at a constant frequency of $1 \mathrm{~Hz}$ under a $20 \mathrm{~N}$ load (Contact pair: steel ball with diameter of $6 \mathrm{~mm}$ ). 


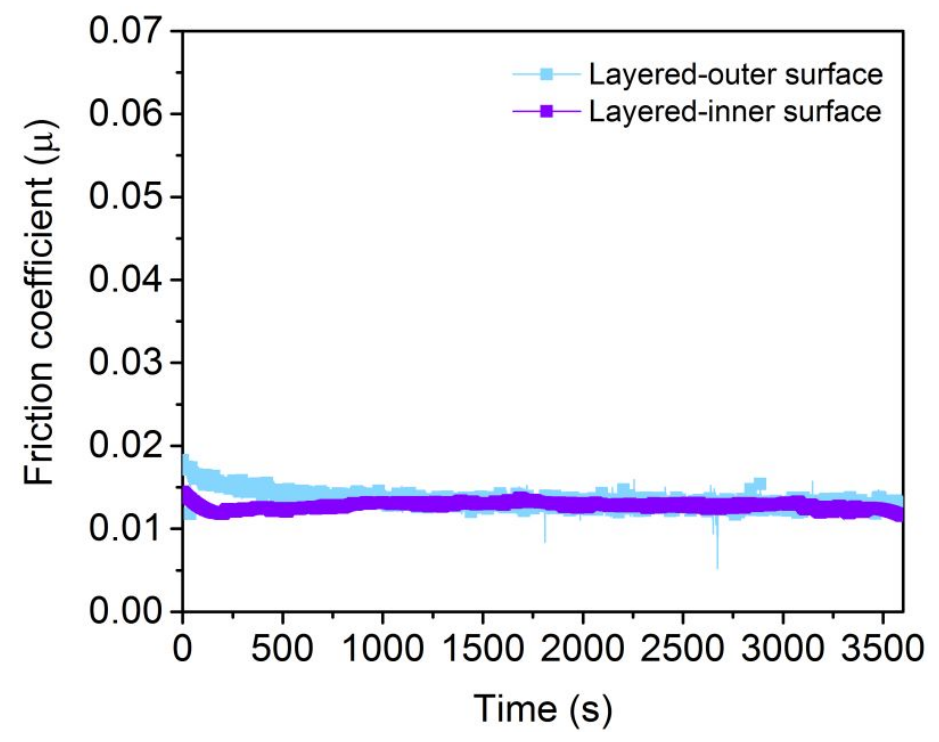

Figure S11. The curves of friction coefficient for outer and inner surface of the layered hydrogel tube at 3600 sliding test cycles.

Table S1. The static average contact pressures $P_{\text {ave }}$ of the layered hydrogels sample (5 min $\mathrm{NaOH}$ treatment) against steel ball $(6 \mathrm{~mm})$ under different loads condition are calculated.

\begin{tabular}{|c|c|c|c|c|c|}
\hline Load $(\mathrm{N})$ & 1 & 3 & 5 & 10 & 20 \\
\hline $\begin{array}{c}\text { Static contact } \\
\text { radium }(\mathrm{mm})\end{array}$ & 0.56 & 0.69 & 0.84 & 1.15 & 1.45 \\
\hline$P_{\text {ave }}(\mathrm{MPa})$ & 1.02 & 2.01 & 2.26 & 2.41 & 3.03 \\
\hline
\end{tabular}

